\title{
ÁLVARO CUNQUEIRO NO SEO DO GALEGUISMO
}

María Dolores Villanueva Gesteira

Universitat de Barcelona

doi:10.17075/mucnoc.2014.013 

Forcadela, M. / T. López / D. Vilavedra (coords.) (2014): Mil e un cunqueiros. Novas olladas para un centenario, Santiago de Compostela, Consello da Cultura Galega. doi:10.17075/mucnoc.2014. pp. 283-294

Nestas páxinas pretendemos debuxar a traxectoria vital de Álvaro Cunqueiro tendo como referencia o galeguismo, aínda que só poderemos tratar algúns puntos, sobre os que intentaremos botar luz e iluminar, así, algunhas caras da poliédrica singradura vital do escritor de Mondoñedo. Comezaremos por aclarar que, cando falamos de galeguismo, agrupamos todos os movementos que defenden unha identidade propia de Galicia e que non debemos reducir o nacionalismo nin a posicións de esquerdas, pois ten un referente social moito máis amplo.

Álvaro Cunqueiro, na súa mocidade, participa do entusiasmo da República e sabemos do seu vencello a proxectos culturais, pero tamén políticos. Xa en 1930, atopámolo en Mondońedo dirixindo unha folliña baixo o significativo nome de Galiza, fundando a editorial UN, colaborando en Resol ou impulsando a Oficiña Lírica do Leste Galego. A súa comuñón co galeguismo non ten fisuras e non son poucas as ocasións en que lanza un berro de unión ao ideario, como no inicio do «Manifesto» que aparece no segundo número de Galiza:

Unha chamada pra labourar por ises novos e degarados tempos é ista folla: ela é un berro a os fillos da Galiza pra que en pé, sereos, pro tamén con carraxe, se ergan do sono en qué, debruzados, mais morren que viven e, foguendo dos seus peitos firentes proas loiten nos mares da Vida pol-a grandeza e liberdade da Mai-Terra (Cunqueiro 1931: 1 ou 1999: 83).

Nese segundo número, aparecido en 1931, podíanse ler poemas tan significativos como «iEn pé!», de Ramón Cabanillas, con versos que reivindican ideas moi semellantes. Lembremos:

¡Irmáns asoballados

de xentes estranxeiras, ergámo-la bandeira azul e branca!

E ó pé da enseña da nación galega

cantémo-lo dereito

á libertá da Terra! 
Podemos seguir analizando aquela folliña ventureira para facérmosnos unha idea dos intereses do seu director. Se seguimos con este número, atopamos poemas de gran calado simbólico, como «Adeus» de Manuel Antonio, «A nosa bandeira» de Amado Carballo, «Heroica mocedade» de Noriega Varela, «O meu corazón roubóu-mo» e «Coma a unha santiña...» de Aquilino Iglesia Alvariño, «Sant-Iago» de Xulio Sigüenza ou fragmentos do «Himno galego» composto por Pondal. Álvaro Cunqueiro non só dirixía Galiza, tamén escribía nela artigos, ao igual que colaboraba no semanario mindoniense Vallibria ou no xornal El Pueblo Gallego. Todas as vetas creativas beben do mesmo zume, o galeguismo, que está na cerna das súas actuacións.

A actividade xornalística e cultural ramificouse en moitas máis iniciativas e complementou a súa aposta política como militante do Partido Galeguista, compartindo ideario con Bóveda, Castelao, Otero Pedrayo, Risco e tantos outros que ocupaban a primeira plana da organización. Como membro do partido, foi convidado a Barcelona en 1934 polos galeguistas da cidade, unha visita que aproveitou para desenvolver as súas relacións literarias e participar en conferencias e encontros con escritores cataláns. Naquel momento era un poeta vangardista monolingüe en galego con dous poemarios editados: Mar ao norde (1932) e Cantiga nova que se chama ribeira (1933). A súa conexión con Cataluña foi inmediata e mantívose ao longo de toda a súa vida, pero, nos anos previos á sublevación fascista, desenvolveu unha clara preocupación polas linguas minorizadas. Se reparamos nas misivas que lle escribía ao escritor catalán Tomàs Garcés, chama a nosa atención que a lingua de comunicación do de Mondoñedo é exclusivamente o galego, evitando neste período o idioma que lles era común, o castelán. Cunqueiro mostra un interese crecente polo catalán, lingua en que tamén se vai expresar como poeta, e esta alofonía lémbranos irremediablemente ao poeta Federico García Lorca e a súa incursión en galego cos seus famosos Seis poemas galegos (1935).

Ninguén pode negar a complicidade de Álvaro Cunqueiro co galeguismo na época republicana e, aínda que mantiña unha posición contraria ao pacto de esquerdas, defendeu ata o último día que foi posible o Estatuto de autonomía. Por iso non nos resultan estrańas, seguindo o fío da historia, as palabras que lle escribe ao seu íntimo amigo Felipe Fernández Armesto (Augusto Assía) días despois do alzamento militar, nas que se mantén fiel á súa liña de pensamento: 
Ben en serio iprobe España! ¡E probes de nós tamén! Eu non sei ben aínda —vou pra 24 anos - si lle é duro ao home aguantar a sua condizón de home, pro anque eisí fora eu amaría sempre, sober todo, a miña liberdade, i-as liberdades que os homes tivéramos en común e bon reximento serían por min sempre amadas e defendidas (Amoedo López 2010: 303).

Os días posteriores ao 18 de xullo de 1936 foron convulsos e unha decisión atinada podía salvar unha vida. A Cunqueiro comprometíano o seu pasado como membro do Partido Galeguista e todas as actuacións culturais levadas a cabo. Por esta razón, decide afastarse o máis lonxe posible e Ortigueira vai ser o lugar escollido para evitar as represalias que xa estaban padecendo algúns dos seus amigos. Asasinaran a Bóveda ou ao seu editor Ánxel Casal, outros compañeiros víranse obrigados ao exilio e os demais acubilláronse nas casas de amigos para tentaren salvar a vida. Membros da súa familia non tardaron en posicionarse a prol da sublevación e en ocupar cargos relevantes, como o seu tío Francisco Cunqueiro Montenegro, que foi o primeiro alcalde delegado de Orde Pública de Redondela. Non sabemos se isto influíu para non ser un branco do fascismo, pero o que, sen dúbida, contribuíu foi a súa aposta por cargar a pluma e utilizala como arma poderosa para festexar a chegada do réxime fascista. Comezou así a colaborar en Era Azul. Guión de Falange Española y de las J.O.N.S. de Ortigueira, que ve a luz o 12 de novembro de 1936 por vez primeira. As loanzas ao réxime e ao ditador son recorrentes non só nas páxinas dos xornais, senón tamén nos actos públicos aos que era convidado. Quizais por iso é nomeado xefe local de Prensa e Propaganda de Falanxe. Cunqueiro colaborara en El Pueblo Gallego cando o seu propietario era Marcial Valladares e tiña unha liña galeguista, pero, coa sublevación fascista, foi incautado e utilizado para espallar as ideas dos golpistas. Neses primeiros anos, diríxeo Jesús López Suevos, un dos falanxistas galegos con máis poder. Deseguida repara naquel mozo que escribe en Ortigueira e no que ve grandes aptitudes para a escrita, polo que axiña lle ofrece as páxinas do xornal en que tamén van expiar o seu pasado galeguista José Fernando Filgueira Valverde ou Vicente Risco, entre outros. Non sería o director de El Pueblo Gallego o único que sucumbiría aos encantos de Cunqueiro, pois José María Castroviejo y Blanco Cicerón, que asinara a acta fundacional do jonsismo en Galicia xunto con Santiago Montero Díaz, vai ser un dos seus grandes valedores, amais do seu íntimo amigo. Naquel momento, ambos os dous destacaban no eido literario e xornalístico, e nese novo 
ambiente Cunqueiro vai tecendo amizades coas forzas vivas da ditadura. A súa vinculación vai máis aló ao darse de alta na Falanxe en 1937 en Vigo, aínda que nun dos expedientes consta que xa o era desde xuño de 1936, unha manobra que se lle atribúe a López Suevos para non levantar sospeitas, pero da que non hai certeza que non sexa falsa. O que si podemos aseverar é que se dá de baixa en 1943.

O fascismo enxálzao e a súa carreira xornalística parece non ter teito. Os seus artigos propagandísticos da guerra aparecen en $L a$ Voz de España e comeza a asinar colaboracións na revista falanxista Vértice, ata que en 1939 se incorpora ao xornal madrileńo $A B C$. En todos estes anos, a lingua galega permanece esquecida para o escritor de Mondońedo, mesmo en contextos onde sería de agardar, como no prólogo que lle escribe ao libro Fala d'as musas (1936) de Daniel Pernas Nieto. Non deixa de sorprender que, nunha situación tan acaída para o emprego do seu idioma literario ata meses antes, prefira manter a súa marca de escritor monolingüe en castelán. Esta posición afástao dos amigos de preguerra, especialmente dos que non aceptan a ditadura e manteñen a esperanza e a loita pola restauración da República. Con todo, sabemos que segue mantendo relación esporádica con Ramón Piñeiro ou Francisco Fernández del Riego. Este último fala de que "pesie a que nunha época determinada estivéramos alonxados por seguíremos camiños disociados na política, nunca nos afastamos como amigos» (Fernández del Riego 1990: 255-256).

Os galeguistas que non viraran a súa ideoloxía intentaban sobrevivir e reorganizar o Partido Galeguista na clandestinidade, polo que a distancia con Cunqueiro é máis que xustificada. De todas as maneiras, para ser xustos con Álvaro Cunqueiro, habería que dicir que o seu comportamento non foi illado dentro do galeguismo, pois houbo máis nomes que, por razóns diferentes, apostaron pola sublevación fascista. Xa nomeamos a Filgueira Valverde e a Vicente Risco, pero tamén hai que incluír a Celso Emilio Ferreiro, nos primeiros anos, ou a Álvaro de las Casas, entre outros.

Cunqueiro, malia ter unha pluma brillante, tardará pouco en caer en descrédito por cuestións xa ben coñecidas e quizais por outras que nos escapan. Será nese momento cando regrese a Mondońedo co fardel cargado de decepcións, pero deseguida sente o apoio das amizades galeguistas, que intentan dignificar a súa persoa reincorporándoo ao proxecto que iniciara antes da Guerra Civil. Cunquei- 
ro, sabedor de que a súa sombra era moi alongada, comeza a escribir sobre temas galegos grazas a Francisco Fernández del Riego, que lle abre as portas de La Noche:

Viñeron despois andaduras desnortadas. Pero no 1945 comezou a deixar todo o que o alonxara de Galicia. Encetou daquela a colaboración nos xornais sobre temas relativos ao propio país. Foi cando reanudamos a vella comunicación epistolar. Vencendo a súa teimosía de se mergullar nun mundo de escepticismo e de soedade, animeino, tamén eu cismante, para que escribise prosa en galego. Foi, mesmamente polo meu petarreo, que se decidira a facer narrativa na lingua natal. Xurdiron así, de a pouco, os folios cos que compuxo o libro Merlín e familia. Disfrutamos xuntos, máis tarde, de xeiras e viaxes inesquecibles (Fernández del Riego 1990: 255).

Os galeguistas que mantiveron unha boa relación con Cunqueiro, como Fernández del Riego, evitan afondar nun pasado fascista e prefiren sumir todos eses anos de vencello co réxime nunha nebulosa, como se o autor sufrise unha alienación mental transitoria froito da barbarie da guerra e os cambios tan convulsos aos que non se soubera adaptar. En Mondoñedo, recobra o compás que lle marca novamente o rumbo galeguista e, para os amigos, Cunqueiro reencóntrase coa súa verdadeira identidade, a galega, que desde entón reivindicou. Non podemos negar que o regreso a Galicia foi un punto de inflexión na traxectoria do escritor, pero non quere isto dicir que rachase definitivamente co réxime, xa que mantivo boas relacións con persoas afíns a el. Desta maneira, da man de Leal Insua, entra no Faro de Vigo, xornal do que chega a ser director entre 1965 e 1970. Desde a súa posición de mando, ten que manter un equilibrio entre a censura e a amizade, sabedor de que é un fío moi feble. Así, Valentín Paz-Andrade, que escribía nas páxinas do xornal unha serie de artigos sobre os problemas socioeconómicos de Galicia cando Cunqueiro asumira a dirección, tivo que deixar de facelo:

Unha mañá escoitei a súa voz [a de Cunqueiro] polo arame dándome a entender que o editorial daquel día, nalgunha esfera oficial, non caera ben. Considerei que a chamada podía envolver necesidade ou desexo de volver ao réxime do silencio e renunciei a manterme a cabalo da pluma denantes de ser pola forza desmontado (Calvo 2011: 325).

O verdadeiro cambio do escritor foi a súa reincorporación ao sistema literario galego, pero xa non como poeta vangardista, senón como narrador de obras fundamentais. Cunqueiro participa do proxecto de construción narrativa que tanto 
preocupaba á Editorial Galaxia, para a que el escribirá obras tan significativas como Merlín e familia (1956), As crónicas do Sochantre (1956), O incerto señor don Hamlet, principe de Dinamarca (1958), Escola de menciñeiros (1960), Se o vello Sinbad volvese ás illas (1961), Xente de aqui e de acolá (1971) e Os outros feirantes (1979). A Editorial Galaxia fora fundada en 1950 por Francisco Fernández del Riego e Xaime Illa e, desde a súa botadura, tińa o firme propósito de revitalizar a lingua e a cultura galegas, unha vez que esgotaran os intentos de reorganización política. Eran moitas as preocupacións, pero entre elas estaba a consolidación dunha prosa que mirase cara a Europa, con carácter universal e anovadora. Cunqueiro levou a cabo a gran cruzada da imaxinación que Galaxia reclamaba:

[...] andado o tempo, Cunqueiro volveu ó rego que abandonara. Penso que a miña teimosía foi decisiva neste particular. Animeino a se reintegrar ó mundo da cultura, á lingua que, malia todo, non esquecera. Venceu os riscos da soidade deprimente que o envolvía. Reviviu no amor á fala, á creación literaria. Trouxo á literatura galega renacida novos aires de orixinalidade na narración, no teatro, mesmo en traballos didácticos (Fernández del Riego 2003: 203-204).

A xenerosidade do galeguismo permitiu que puidesen convivir represaliados e persoas que apoiaran e tiveran vinculación cos represores. Quizais no caso de Cunqueiro é especialmente paradigmático, porque houbo unha especie de bula entre os seus compańeiros, mesmo entre aqueles que se viran obrigados ao exilio, como Luís Seoane, e non sempre eran tan comprensivos:

Recibí estos días el nuevo libro de Cunqueiro de Galaxia, que supongo tan bueno a simple vista — pues aún no lo leí— como los últimos suyos. Haré, como siempre con todo lo que llega de ahí, el comentario radial (Luís Seoane a Fco. Fernández del Riego, Bos Aires, 1 de abril de 1959).

Anos despois, segue loando a escrita, pois escribe que «El libro de Cunqueiro me pareció el mejor de los publicados últimamente por él y muy bueno el prólogo de Domingo» (Luís Seoane a Fco. Fernández del Riego, Bos Aires, 8 de marzo de 1961). Nas referencias que nesta época se fan a Cunqueiro sempre se recorre á súa escrita, á súa calidade literaria e inténtase minimizar a súa vinculación co réxime. Sempre atopan unha razón para xustificar as súas reaccións e normalmente recorren á súa personalidade infantil, feble, que non distingue con claridade o ben 
do mal. Hai moitos exemplos de comentarios ao respecto, pero podemos recoller este que responde moi ben aos parámetros aquí debullados:

Coido que a madurez e a vellez o atinxiron sen penetrar no cerne da súa alma infantil, e que a traxedia de Espańa que o embrullou nos seus loitos, non lle destruíu a naturalidade de fantasía dos dons de transparencia ditosa que posúen os descendentes daquela que non probou o froito da ciencia do ben e do mal (Carballo Calero 1981: 133-134).

Este convivium aínda parece máis evidente nesta carta escrita por Eduardo Blanco Amor, na que ademais ofrece algunhas claves sobre a escrita de $A$ Esmorga. Confesións á marxe, interésanos a nómina de autores aos que lle envía a súa obra e dos que agarda unha opinión que posiblemente non lle chegou nunca:

A Esmorga mandeina ós seguintes escritores: «Borobó», V. Risco, C. Martínez Barbeito, C. J. Cela, J. Sigüenza, R. Carballo Calero, Iglesia Alvariño, A. Cunqueiro, L. López Cid, A. Fole (que se ocupóu dela, tí me mandache o recorte), Filgueira Valverde, Guerra Dacal, e fai uns días, por indicación de Piñeiro, ó rapaz López [sic] Ferrín, do xuntoiro Brais Pinto. Coido que a distribución foi bastante abondosa. A mińa queixa está inspirada en que non hai proporción entre iste silenzo e o barullo que se arma cando o libro sae eí publicado (Carta de E. Blanco Amor a Fco. Fernández del Riego, Bos Aires, 8 de abril de 1960).

Ata este momento, parece que Cunqueiro era visto dentro do galeguismo como un bon vivant incapaz de adaptarse á realidade e, polo tanto, sen responsabilidade sobre os seus actos. Esta imaxe é parcial xa que houbo quen recriminou con furia as actitudes de Cunqueiro e, sen dúbida, un dos máis belixerantes foi Celso Emilio Ferreiro, quen nos primeiros anos do franquismo fora empregado da Fiscalía de Taxas, pero que xa neste momento estaba lonxe da ditadura e próximo a posicións comunistas. Celso Emilio e Cunqueiro trabaran unha amizade antes e despois da Guerra Civil, pero o autor de Longa noite de pedra rompe a súa relación co mindoniense e tamén con Luís Seoane e Fernández del Riego nesta época. Quizais as diferenzas literarias e políticas alimentaron a distancia persoal e así se deixa ver na "Carta a Cunqueiro» que Celso Emilio fixo chegar a numerosas persoas e na que lle dirixe palabras tan duras como as que seguen:

Por unha circunstancia fortuita [...] poiden istes días enteirarme de que, facendo gala da túa propensión á felonía quimicamente pura, adicaches algún tempo a difamarme 
ante certos ananos da emigración, co fin de adular servilmente ós seus instintos beocios e darlle mantenza nutritiva ao odio cerril con que me distinguen (e me honran) [...]. E pra que teńas a seguridade de que si algún día sintes que se derruba o teito onde te acubillas ao mellor o derrubador principal son eu, e non te chames a engano (Armesto Faginas 1987: 260).

Para Celso Emilio, nesta época non tiñan xustificación episodios como a visita de Cunqueiro a Bos Aires, en 1967, co xeneral Constantino Lobo Montero, presidente do Centro Galego de Madrid e persoa afín ao réxime. Tampouco entendía a súa evasión literaria, posto que el apostaba por unha literatura social que espertase o país e falase da angustia das xentes. Esta liña de recriminación a Cunqueiro seguírona os galeguistas máis novos, como Méndez Ferrín, e proseguiu nas seguintes xeracións, ata que os poetas dos oitenta se reencontraron co poeta de Herba aqui e acolá ou de Dona do corpo delgado e quedaron seducidos pola súa escrita. Quizais sería a imaxe que máis lle gustaría ao autor, que se consideraba, ante todo, un poeta dado á imaxinación e á fantasía:

Para mais, cando o poeta que se dispón a falar é, coma eu son, un home escasamente ouxeitivo, muy levado de istantes i-emociós, e fiñalmente apaixoado na percura da Poesía, e reconocéndoa por mui mesta e impura que se ofereza, agasallándoa e recibíndoa, i-humildosamentes espondéndolle ó seu rosto humán, e pólo mesmo que o tén, e feito con verbas, que son a un tempo a sua morte i-a sua resurreición (Cunqueiro 1958: 12).

As xeracións que viñeron despois de Cunqueiro recoñecen cada vez máis a súa valía como escritor, aceptan sen complexos o seu pasado fascista e son capeaces de mirar con distancia e con rigor a súa obra. Para rematar, imos escoller as palabras do escritor Suso de Toro, que recońeceu que na mocidade renegaba de Cunqueiro, pero, pasado o tempo, asume esa imaxe de escritor incapaz de axustarse á realidade:

Cunqueiro medrou e fíxose maior fantaseando. O que caracteriza ás persoas adultas é a renuncia a soñar. Facérmonos adultos é aceptar unha vida que chamamos a «normalidade» baseada nesa renuncia. Cunqueiro nunca aceptou ese trato para facerse home e foi un Peter Pan nun tempo moi cruel, a facer por voar e enredando as ás nas silveiras. Realmente os escritores do sońar fan un oficio. Cunqueiro era incapaz de limitarse a soñar por horas e viviu nun estadio de vida imaxinaria estupefaciente. Non 
se fugaba da realidade, simplemente permaneceu dentro dunha boia transparente, na súa realidade particular e nun tempo histórico propio no que convivían figuras doutros séculos e libros de todas as épocas.

O galeguismo soubo recońecerlle a Cunqueiro a súa sublime literatura e, grazas a iso, puido superar o maniqueísmo e poñer nomes e apelidos ás etapas vitais do escritor. Hai que falar de fascismo, pero tamén de galeguismo, de compromiso, de entrega, de lingua, de país e dun proxecto de reconstrución da cultura galega no que é pedra angular. Segue dicindo Suso de Toro:

Cunqueiro viviu a súa vida como literatura. Foi galeguista e fascista logo, foi un escritor de xornalismo incansábel e un pícaro, e todo parte do mesmo sońo do meniño a ler nun cuarto de Mondońedo. Énos imprescindíbel, proba de que a literatura en lingua galega pode e debe existir en por si, sen outra xustificación fóra de si mesma. Sen xustificación ningunha ${ }^{1}$.

Leamos, pois, a Cunqueiro porque na súa obra está a mostra máis evidente e incuestionable do seu galeguismo. 


\section{REFERENCIAS BIBLIOGRÁFICAS}

Allué Andrade, X. L.: Cartas a un mozo galego. Correspondencia con Xosé Luis Allué 1953-1967, Vigo, Editorial Galaxia, 2005.

Alonso Girgado, L. et alii (ed.): Ramón Piñeiro: Epistolario lugués. Cadernos Ramón Piñeiro XV, Santiago de Compostela, Xunta de Galicia, 2010.

Alonso Montero, Xesús: «Álvaro Cunqueiro: tres poemas en catalán e unha carta en galego a Tomàs Garcés», en J. Cerdà, V. Martínez-Gil e R. R. Vega (eds.), 2003, pp. 11-30.

Amoedo López, Gonzalo: A memoria e o esquecemento. O franquismo da provincia de Pontevedra, Vigo, Edicións Xerais de Galicia, 2010.

Armesto Faginas, Xosé F.: Cunqueiro: unha biografía, Vigo, Edicións Xerais de Galicia, 1987.

BALAguer, Josep M.: «Els primers contactes de Cunqueiro amb el món cultural català i algunes conseqüències», en J. Cerdà, V. Martínez-Gil e R. R. Vega (eds.), 2003, pp. 53-86.

Calvo, Tucho: Valentín Paz-Andrade, a memoria do século XX, Cesuras, Biblos Clube de Lectores, 2011.

Carballo Calero, Ricardo: «Para o doutor Cunqueiro», Grial, 72 (1981), pp. 133-136.

Cerdà, J.; V. Martínez-Gil e R. R. Vega (eds.): Álvaro Cunqueiro e as amizades catalanas, Sada, Ediciós do Castro, 2003.

Cunqueiro, Álvaro: «A recuperación literaria do galego», en A. Cunqueiro, Ensaios IV, Vigo, Galaxia, 1991, pp. 31-37.

Cunqueiro, Álvaro: «Limiar», en E. Moreiras, Paisaxe en rocha viva, Vigo, Galaxia, 1958, pp. 12-14.

Cunqueiro, Álvaro: Cartas ao amigo. Epistolario mindoniense a Francisco Fernández del Riego 1949-1961, Vigo, Galaxia, 2003.

Cunqueiro, Álvaro: Galiza. Mondoñedo (1930-1933). Edición facsimilar. Santiago de Compostela, Centro Ramón Piñeiro para a Investigación en Humanidades, 1999.

Fernández del Riego, Francisco: Camiño andado, Vigo, Galaxia, 2003.

Fernández del Riego, Francisco: O río do tempo. Unha historia vivida, Sada, Ediciós do Castro, 1990.

Franco Grande, Xosé Luís: Os anos escuros, Vigo, Galaxia, 2004.

MARTíneZ-GiL, Víctor: «Álvaro Cunqueiro en els escriptors catalans: una imatge de Galícia», en J. Cerdà, V. Martínez-Gil e R. R. Vega (eds.), 2003, pp. 185-210.

Neira Vilas, Xosé: Cartas de vellos amigos 1959-1998, Vigo, Editorial Galaxia, 2010.

PIÑ́EIRo, Ramón: «Carta a Álvaro Cunqueiro, trovador galego falándolle dos males presentes de Europa e do seu remedio, dende a ladeira dun castro lugués», Cadernos Grial, 3 (1951), pp. 103-107.

PIÑ́eIro, Ramón: «Carta a don Manuel Rodrigues Lapa», Grial, 42 (1973), pp. 389-402.

PIÑ́EIro, Ramón: «Cultura e política», Grial, 111 (1991), pp. 377-381.

PiñeIro, Ramón: Do sentimento á conciencia de Galicia. Correspondencia (1961-1984), Vigo, Galaxia, 2009.

\section{PÁXINAS WEB}

http://www.elpais.com/articulo/Galicia/Cunqueiro/sen/compromiso/elpepuespgal/20111223elpgal_13/Tes

http://www.elpais.com/articulo/Galicia/Celso/Emilio/Cunqueiro/elpepiautgal/20111014elpgal_20/Tes 